\title{
Human Brain Arteriovenous Malformations are Associated with Interruptions in Elastic Fibers and Changes in Collagen Content
}

\author{
Insan Beyin Arteriövenöz Malformasyonlarn Elastik Liflerde Kesintiler \\ ve Kollajen İ̧eriğginde Değişikliklerle İlişsilidir
} \author{
Yuan-Li $\mathrm{ZHAO}^{1}$ \\ ${ }^{1}$ Capital Medical University, Beijing Tiantan Hospital, Department of Neurosurgery, Beijing, China \\ ${ }_{2}^{2}$ Peking Union Medical College, Department of Neurosurgery, Beijing, China \\ ${ }^{3}$ Ankara Numune Education and Research Hospital, Department of Neurosurgery, Ankara, Turkey \\ ${ }^{4}$ Baoding No.1 Hospital, Department of Radiology and Imaging, Baoding, China \\ ${ }^{5}$ Capital Medical University, Department of Neuropathology, Beijing, China \\ ${ }^{6}$ China-Japan Friendship Hospital, Institute of Clinical Medicine, Beijing, China
}

Yi GUO ${ }^{1}$, Shi-Wei $\mathrm{QUMU}^{2}$, Osman Arikan NACAR ${ }^{3}$, Jin-Yan YANG ${ }^{4}$, Jiang DU ${ }^{5}$, Deniz BELEN ${ }^{3}$, Lin PAN PAN $^{6}$

Presented in: Part at the Eighth Asian Congress of Neurological Surgeons, Kuala Lumpur, Malaysia on Nov. 21, 2010.

Correspondence address: Yuan-Li ZHAO / E-mail: zhaolang88@hotmail.com

\begin{abstract}
AIM: We hypothesized that the loss of structural integrity in vessels of brain arteriovenous malformations (bAVM) is associated with abnormal expression of collagen subtypes.

MATERIAL and METHODS: We retrospectively obtained the nidus tissue specimens from 24 bAVM patients and structurally normal cerebral cortex from six surgical epilepsy patients. The samples were paraffin-embedded and stained with Victoria blue and picrosirius red and examined by light microscopy.

RESULTS: Light microscopy showed that collagen fibers became disorganized, and the internal elastic lamina was duplicated or interrupted in the arteries from the nidus tissue of bAVM. In some vessels in the nidus, Col I was the only collagen component and the interstitial tissue was mainly comprised of Col I. bAVM patients showed significantly higher Col I levels $(86.25 \% \pm 13.92)$ and lower Col III levels (13.75\% \pm 13.92$)$ in the vasculature in the nidus tissue than those of otherwise normal surgical epilepsy patients (Col I, $80.78 \% \pm 18.03 ;$ Col III, 19.22\% \pm 18.03 ) $(p<0.001)$. Additionally, bAVM patients showed a higher Col I / Col III ratio $(24.71 \pm 40.47)$ than that of normal controls $(16.04 \pm 31.28)(p<0.001)$. CONCLUSION: bAVM patients exhibit changes in the Col I/Col III ratio and elastic fibers in the vasculature, which may compromise the structural integrity of cerebral vessels.
\end{abstract}

KEYWORDS: Arteriovenous malformation, Collagen, Elastic fibers

öz

AMAÇ: İnsan beyin arteriövenöz malformasyonlarındaki (bAVM) damarların yapısal bütünlüğünün bozulmasının, kollajen alttiplerinin anormal ekspresyonu ile ilişkili olabileceği hipotezini kurduk.

YÖNTEM ve GEREÇLER: bAVM'li 24 hastanın nidüs doku örnekleri ile epilepsi cerrahisi uygulanan 6 hastanın yapısal olarak normal olan serebral korteks dokusu elde edildi. Örnekler parafine gömüldü ve Victoria mavisi ve Picro-Sirius Red boyaları ile boyanıp ışık mikroskobu altında incelendi.

BULGULAR: Işık mikroskopu altındaki incelemede bAVM nidus arterlerindeki kollajen liflerinin düzenlerinin bozulduğu ve internal elastik tabakanın da kesintiye uğradığı veya duplike olduğu saptandı. Nidustaki bazı damarlardaki tek kollajen yapısının Col I olduğu ve interstisyal tabakanın ağırlıklı olarak Col I'den oluştuğu saptandı. bAVM hastalarında kontrol grubuna (Col I, \%80,78 $\pm 18,03$; Col III, \%19,22 $\pm 18,03$ ) göre nidus damarlarındaki Col I düzeylerinin anlamlı olarak yüksek olduğu (\%86,25 \pm 13.92$)$, Col III düzeylerinin ise anlamlı olarak düşük olduğu $(\% 13,75 \pm 13.92)$ bulundu $(p<0,001)$. Ek olarak bAVM hastalarında Col I / Col III oranı $(24,71 \pm 40,47)$, kontrol grubuna göre $(16,04 \pm 31,28)$ anlamlı olarak yüksekti $(p<0,001)$.

SONUÇ: bAVM'li hastaların nidus damarlarında Col I / Col III oranında ve elastik liflerde değişiklikler mevcuttur ve bu durum serebral damarlardaki yapısal değişimlerin nedeni olabilir.

ANAHTAR SÖZCÜKLER: Arteriövenöz malformasyon, Elastik lifler, Kollajen 


\section{INTRODUCTION}

Intracerebral hemorrhage accounts for approximately $10-15 \%$ of strokes and is associated with high early mortality. Vascular malformations of the brain, including arteriovenous malformations, remain one of the important causes of intracerebral hemorrhage, which also include, among others, head trauma, chronic hypertension amyloid angiopathy, bleeding into primary or metastatic tumors, and coagulopathy. Brain arteriovenous malformations (bAVM), which are different from other cerebral vascular malformations such as venous angiomas and cavernous hemangiomas, are abnormal vascular structures composed of tortuous arteries and dilated veins. BAVM was thought in most cases to be congenital, originating from embryonic developmental failure of the intervening capillary beds. However, they typically present in middle age and appear to grow over time (3). Hitherto, the molecular mechanisms that underlie the formation and growth of bAVM remain largely unelucidated.

The extracellular matrix (ECM) is a major component of blood vessel walls and provides structural support to the blood vessels. The ECM is composed of collagens, elastins, and glycosaminoglycans with collagen being one of the most abundant fibrous proteins in the ECM. Collagen has two common arterial subtypes, type I (Col I) and type III (Col III) $(8,22)$. The combination and organization of these collagen subtypes maintain the function, integrity, and strength of blood vessels (1). An increase in the Col I/Col III ratio has been associated with cardiovascular disease $(13,16,21)$, and disequilibrium in collagen subtypes has also been implicated in the pathogenesis and rupture of intracranial aneurysms and hemodynamic stress $(14,17,25)$.

BAVM is a leading cause of spontaneous intracranial hemorrhage in young adults. Reported annual hemorrhage incidence for bAVM is $2-32.6 \%$ (4). Possible hemorrhagic risk factors include size, location, and angioarchitectural and morphological characteristics of $\operatorname{bAVM}(6,9,24)$. Among these factors, histopathological changes of vascular walls are the structural basis of bleeding. In addition, patients with bAVM show a variable clinical course, particularly with respect to spontaneous hemorrhage, recurrence, growth, and regression, suggesting that bAVM is structurally unstable vessels. It remains unknown if changes in the Col I / Col III ratio are present in the vessels of bAVM. We speculate that derangement of collagen subtype ratio in the vasculature of bAVM may result in the destabilization of vessels, which potentially leads to weakening of the vessel wall, passive dilatation, and rupture. To test the hypothesis that vascular instability in bAVM is associated with abnormal expression of collagen subtypes, we examined the vascular structure and the expression of Col I and Col III in the nidus tissue of bAVM.

\section{MATERIAL and METHODS}

\section{Acquisition of tissue specimens}

We retrospectively obtained specimens from 24 patients who underwent surgical resection for bAVM between February
2009 and April 2010 at Tiantan Hospital, Capital Medical University, Beijing, China. The nidus of bAVM was dissected away from any adjacent brain tissue in the operating room, and a representative portion of the nidus tissue was used for further analysis. All nidi were located on the convex surface of the cerebral hemisphere. For the control group, structurally normal cerebral cortex tissues were obtained from six patients undergoing temporal lobectomy for medically intractable seizures. Acquisition of tissue specimens was approved by the Capital Medical University Institutional Review Board and the study was carried out in strict accordance with the institution guidelines on human tissue acquisition and use.

\section{Victoria blue and picrosirius red staining}

Surgically resected tissue specimens of bAVM and normal control tissues were fixed in formalin and embedded in paraffin and then sectioned ( $4 \mu \mathrm{m}$ thick). All sections were stained with Victoria blue and picrosirius red as described previously (15). Briefly, the paraffin sections were deparaffinized and rehydrated in distilled water. After a wash with $70 \%$ ethanol for $2 \mathrm{~min}$, sections were stained in Victoria blue solution for 12 $\mathrm{h}$ at $37^{\circ} \mathrm{C}$. They were then briefly washed with $95 \%$ ethanol for several seconds and distilled water for 2 min before staining with $1 \%$ picrosirius red F3BA (Sigma, Shanghai, China) for $1 \mathrm{~h}$. The sections were then washed in running tap water for 10 min before they were dehydrated, cleared, and mounted.

\section{Microscopy and photomicrography}

Victoria blue and picrosirius red stained slides were visualized under an Olympus BX51 microscope (Olympus, Japan) under bright field or polarized light. Blood vessels at the edges of the nidus tissue of bAVM were excluded from the analysis. The collagen content of blood vessels within the nidus tissue of arteriovenous malformations was measured under polarized light as previously depicted $(20,29)$. Briefly, eight random fields were analyzed for each sample with $a \times 20$ objective lens. Fixed parameters of image-acquisition were used to correct potential variability in staining intensity of sections from different staining batches. For evaluation of changes in collagen subtype in the blood vessels of bAVM, normal control vessels were matched to abnormal vessels by vessel diameter. Under polarized light, Col I fibers are orange-red, whereas the thinner Col III fibers appear yellow-green (21). The hue range of red-orange was defined as 0-37 and yellow-green as 38-127 as modified by Rich et al. (20). For each random field, the area of each hue range was quantified using the ImagePro Plus software (Media Cybernetics, Bethesda, MD). The contents of the two collagen subtypes were represented by the percentage of the area of each hue range. Because it is difficult to distinguish between arteries and veins and layers of the vascular wall in vessels in bAVM, we quantified the collagen content of the entire vascular wall of both arteries and veins rather than in specified layers of arteries $(21,26)$.

\section{Statistical analysis}

All data were expressed as mean \pm standard deviation. Patient characteristics were compared using the $X^{2}$ tests. 
Collagen distributions between the control group and the non-hemorrhage or hemorrhage brain arteriovenous malformation group were compared using Mann-Whitney $\mathrm{U}$ tests. $\mathrm{P}<0.05$ was considered statistically significant. Data were analyzed using SPSS 15.0 (SPSS Inc, Chicago, IL.).

\section{RESULTS}

\section{Patient demographic and lesion characteristics}

We analyzed the tissue specimens from 24 patients with bAVM (14 men and 10 women) and 6 surgical epilepsy patients (4 men and 2 women). The mean age for patients with bAVM and surgical epilepsy patients were $33 \pm 13$ and $32.50 \pm 7.06$ years, respectively. Patient demographic and lesion characteristics are summarized in Table I. The patients with bAVM had a history of headache or epilepsy at presentation. One patient had previously undergone preoperative embolization therapy. The interval between embolization and surgery was 2 days. Eight patients $(33.33 \%$; 8 / 24) had a history of hemorrhage from bAVM. The interval between hemorrhage and surgery was $2 \pm 2$ days (range, 1 to 7 days). None received radiosurgery. Two patients, whose lesions were primarily supplied by the middle cerebral artery (MCA), had coexisting arterial aneurysms, which were confirmed by preoperative digital subtraction angiography and intraoperative findings. One of these patients had a history of hemorrhage and had anterior choroidal artery and MCA aneurysms. The other patient had no history of hemorrhage and had an anterior communicating artery aneurysm.

\section{Collagen fibers are disorganized in blood vessels in the nidus of bAVM}

To investigate whether the blood vessels in bAVM exhibited a different profile in collagen content, we first examined the integrity of the vasculature in the nidus tissue of bAVM. Light microscopic examination of Victoria blue and picrosirius red stained tissue sections showed that normal small cerebral artery from otherwise normal surgical epilepsy patients showed three distinct layers: the intima, media, and adventitia (Figure 1A) and the internal elastic lamina was continuous and separated the media from the intima. Few elastic fibers were observed in the media. Most undulated adventitial collagen fibers had an axial orientation. In addition, no elastic fibers or scattered elastic fibers were present in the media of veins, which was comprised of organized smooth muscle cells surrounded by a collagen network instead. By contrast, the arteries from the nidus tissue of bAVM showed marked changes in collagen and elastic fiber organization. The collagen fibers became disorganized, and the internal elastic lamina was duplicated or interrupted (Figure1B). In some hyalinized arteries, elastic fibers were absent.

\section{Blood vessels in the nidus of bAVM show significant increase in collagen type I to III ratio}

To further investigate whether the disruptions in collagen fibers in the vasculature of the nidus tissue of bAVM was associated with a different profile in collagen content from that of normal controls, we determined the content of Col I and Col III in the blood vessels under light microscopy using polarized light. In normal cerebral artery and vein tissues from otherwise normal surgical epilepsy patients, Col III, which exhibits yellow-green birefringence, was the predominant subtype found in veins and some parts of small arteries, and Col I, which exhibits orange-red birefringence, was found in the walls of small arteries (Figure 2A). By contrast, in some vessels in the nidus tissue of bAVM, Col I was the only collagen component (Figure 2B, C) and the interstitial tissue was mainly comprised of Col I.

Patients with bAVM showed significantly higher Col I levels $(86.25 \% \pm 13.92 \%)$ and lower Col III levels (13.75\% $\pm 13.92 \%)$ in the vasculature in the nidus tissue than those of otherwise normal surgical epilepsy patients (Col I, $80.78 \% \pm 18.03 \%$; Col III, 19.22\% $\pm 18.03 \%$ ) ( $<$ < 0.001) (Table I and Figure 3). Additionally, patients with bAVM showed a markedly higher Col I / Col III ratio $(24.71 \pm 40.47)$ than that of normal controls (16.04 \pm 31.28$)(p<0.001)$ (Table I and Figure 4). Furthermore, patients with bAVM and a positive history of brain hemorrhage $(\mathrm{n}=8)$ showed higher Col I levels $(86.25 \% \pm 13.92 \%)$ and lower Col III levels $(13.75 \% \pm 13.92 \%)$ in the vasculature in the nidus tissue than those without a history of cerebral hemorrhage $(n=16)(C o l l, 80.78 \% \pm 18.03 \%$; Col III, $19.22 \% \pm$ $18.03 \%)$ though no significant statistical difference was noted $(p>0.05)$ (Figure 3). Patients with bAVM and a positive history

Table I: Demographic and Clinical and Collagen Area Data Related to Initial Presentation in Patients with Brain Arteriovenous Malformations with or without Hemorrhage $(n=24)$

\begin{tabular}{|c|c|c|c|}
\hline & Control & Non-hemorrhage & Hemorrhage \\
\hline No. of patients & 6 & 16 & 8 \\
\hline Mean age $\left(\right.$ years) ${ }^{*} \dagger$ & $32.50 \pm 7.06$ & $31.56 \pm 12.37$ & $33.13 \pm 12.16$ \\
\hline Male/female $\ddagger$ & $4 / 2$ & $9 / 7$ & $5 / 3$ \\
\hline Mean maximum vessel dimension $(\mathrm{cm})^{\S}$ & NA & 4.6 & 4.3 \\
\hline Collagen type ${ }^{*}$ & $55.76 \pm 18.06$ & $80.78 \pm 18.03$ & $86.25 \pm 13.92$ \\
\hline Collagen type III* & $44.24 \pm 18.06$ & $19.22 \pm 18.03$ & $13.75 \pm 13.92$ \\
\hline Ratio of Col I/Col III* & $1.69 \pm 1.26$ & $16.04 \pm 31.28$ & $24.71 \pm 40.47$ \\
\hline
\end{tabular}

${ }^{*}$ Mean \pm standard deviation; ${ }^{+} P=0.889 ;{ }^{*} P=0.897 ;{ }^{\circledR} P=0.951$. 


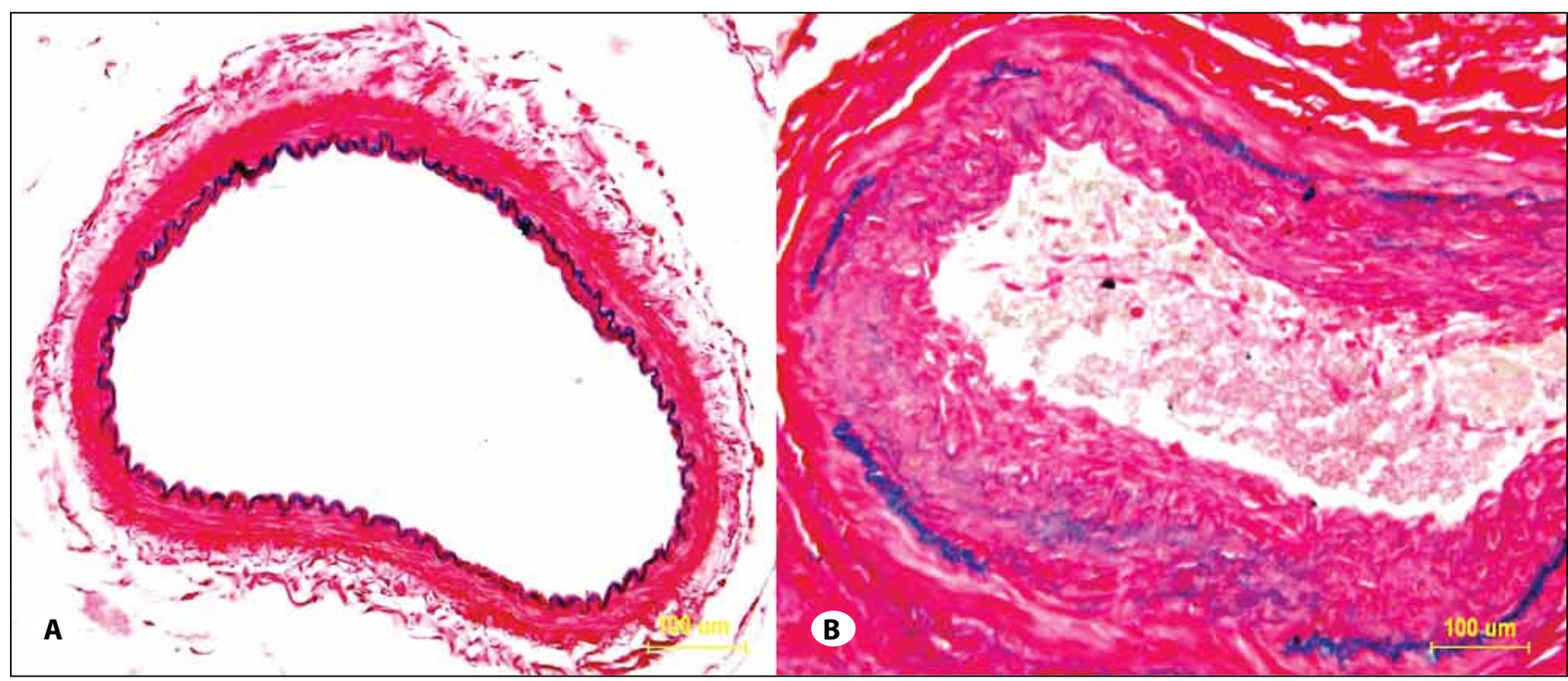

Figure 1: Light microscopy of a normal control blood vessel (A) and a blood vessel in the nidus tissue of brain arteriovenous malformations (B), which were stained with Victoria blue and picrosirius red. Collagen appears red and elastic fibers appear blue in such staining. (A) The normal small cerebral artery shows three distinguishable layers of artery wall and a continuous internal elastic lamina between the intima and media. (B) The abnormal artery from the nidus tissue of brain arteriovenous malformations contains reduplicated, disrupted elastic fibers (blue). Scale bar $=100 \mu \mathrm{m}$.
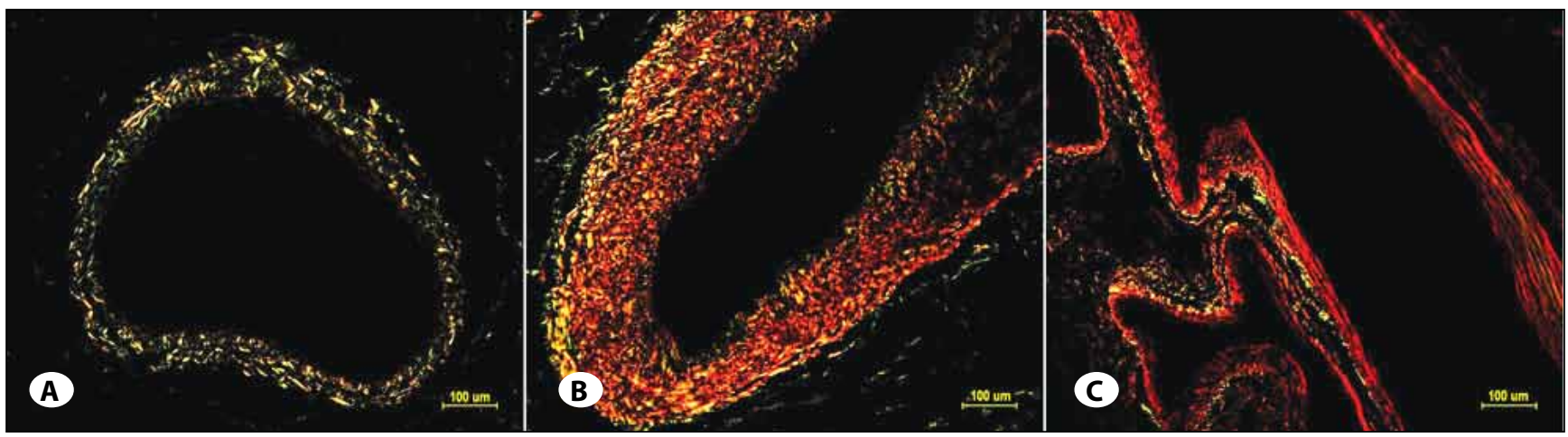

Figure 2: Tissue sections of blood vessels from otherwise normal surgical epilepsy patients (A) and the nidus tissue of brain arteriovenous malformations ( $\mathbf{B}$ and $\mathbf{C}$ ) were stained with Victoria blue and picrosirius red and observed under polarized light. Collagen type I reflects orange/red, and collagen type III reflects yellow/green. Scale bar $=100 \mu \mathrm{m}$.

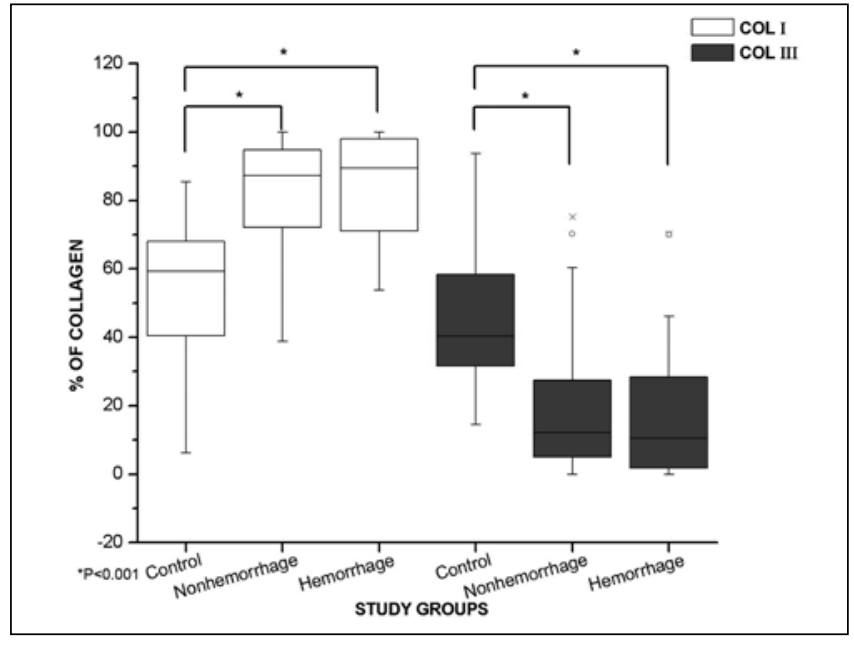

Figure 3: Box plot of collagen type I (Col I) and III (Col III) content in blood vessels from otherwise normal surgical epilepsy patients and the nidus tissue of brain arteriovenous malformations stratified by history of cerebral hemorrhage. ${ }^{*}$ indicates that both Col I and Col III in the vessels of the nidus tissue of brain arteriovenous malformations were at significantly different levels than those of normal control vessels. Error bars represent mean \pm standard deviation. 


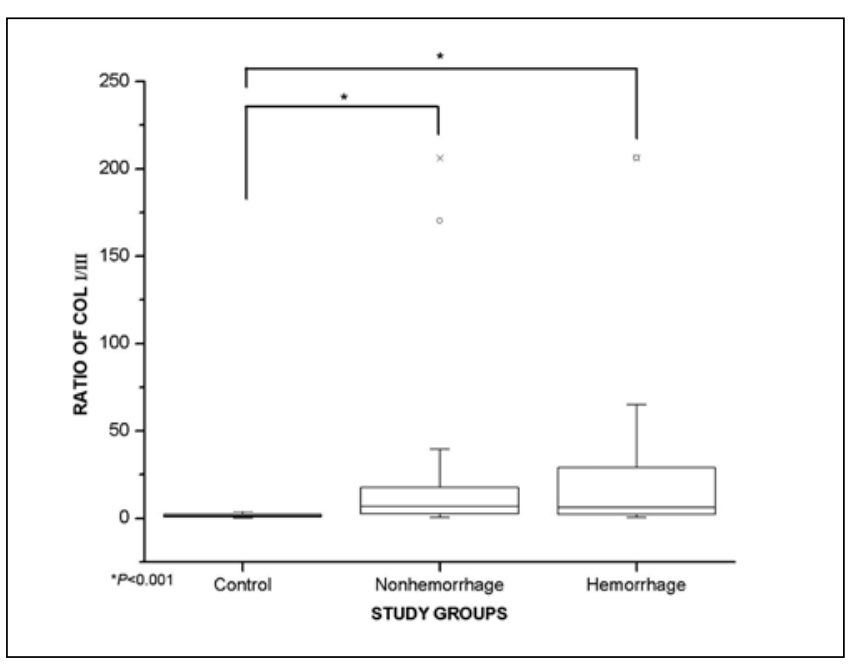

Figure 4: Box plot of the collagen type I and III (Col I/Col III) ratio in cerebral vessels from otherwise normal surgical epilepsy patients and the nidus tissue of brain arteriovenous malformations stratified by history of cerebral hemorrhage. * indicates a significant difference from that of normal control vessels. Error bars represent mean \pm standard deviation.

of brain hemorrhage also showed a higher Col I / Col III ratio $(24.71 \pm 40.47)$ than that of those without a history of cerebral hemorrhage $(16.04 \pm 31.28)$, but no significant statistical difference was found ( $p>0.05$ ) (Figure 4).

\section{DISCUSSION}

In this study, we presented the direct evidence of the abnormal expression pattern of Col I and Col III in bAVM. We found markedly increased Col I and decreased Col III levels in bAVM compared with control brain samples. We further demonstrated that blood vessels in the nidus tissue of bAVM show disorganized collagen fibers and interruptions in the internal elastic lamina. The markedly increased Col I / Col III ratio in bAVM can be expected to cause impairment of the ECM and structural instability of the vasculature in bAVM. This may, in part, explain vascular instability of bAVM. However, a causal relationship needs to be carefully examined in future studies.

Overall, Col I and Col III constitute $60 \%$ and $30 \%$ of the collagen content in arterial walls, respectively. In the media, arterial vessel walls contain approximately $30 \%$ Col I and $70 \%$ Col III, while in the adventitia, Col I is the primary subtype (2). By contrast, the collagen composition of veins is less well studied. We show that Col III is the predominant isotype in normal cerebral veins. However, in bAVM, Col I is the predominant isotype, with some of abnormal vessels consisting almost entirely of Col I.

Fibrosis in these abnormal vessels is found in subjects with or without a history of hemorrhages regardless of preoperative embolization treatment. Although patients with bAVM are a heterogeneous population, this study only includes one subject who had preoperative embolization. Eight of our patients (33.33\%; 8 / 24) had a history of hemorrhage from bAVM; but we found no significant different in Col I and Col III as well as Col I/Col III ratio between those with a history of hemorrhage and those without such a history, suggesting that changes in Col I and Col III contents are unlikely to be associated with the onset of hemorrhage in patients with bAVM. Compared to normal control blood vessels, cerebral vessels in the nidus tissue of patients with BAVM showed a significantly different collagen subtype organization. Although blood vessels in BAVM are heterogeneous, we focused on those vessels within the nidus of bAVM. The arbitrary exclusion of marginal abnormal vessels was a limitation of this retrospective study, and it is possible that these blood vessels had different collagen patterns in hemorrhagic and non-hemorrhagic bAVM.

Because collagen fibers are the primary load bearers in vessel walls, changes in vessel walls are strongly correlated with changes in collagen content, orientation, fiber type, and dimension (5). Col I is a stiff fibrillar protein that provides resistance to tension, whereas Col III forms an elastic network (11) that prevents ruptures in the arterial wall (8). As the Col I / Col III ratio increases so does vascular wall stiffness. In the arteries of bAVM, the internal elastic lamina may be duplicated, interrupted, or completely lost. Therefore, the observed increase in the Col I / Col III ratio in the vasculature of bAVM may compromise the flexibility of cerebral vessels. Combined with venous hypertension in bAVM, these changes may cause bleeding associated with bAVM. Although not significant, the higher Col I / Col III ratio in hemorrhagic sections might also reflect the association between hemorrhage and a loss of blood vessel flexibility in bAVM. This needs to be further addressed in studies with larger sample sizes.

Although intranidal aneurysms and flow-related aneurysms are observed in $16.7-21.0 \%$ of patients with bAVM (19, 23), the actual incidence is likely higher due to aneurysms that are too small to be detected by cerebral angiography (28). The prevalence of aneurysms in patients with bAVM is due to congenital disorder, vascular developments, and hemodynamic stress $(12,17)$. Although we had a small sample size $(n=2)$, we suspect that an increased Col I/Col III ratio might cause the association between bAVM and arterial aneurysms, as this increased ratio has also been observed in patients with intracranial aneurysms $(14,17,25)$.

This study was limited to changes in collagen subtypes within the nidus of bAVM. However, the primary bleeding site may be in peripheral regions of bAVM, such as the feeding arteries, draining veins, or abnormal microcirculation surrounding the nidus. Though picrosirius red staining is one of the best understood and a well-accepted histochemical technique for collagen research $(7,10,18,27)$, further specific studies are required to understand collagen changes in bAVM.

\section{CONCLUSIONS}

In this retrospective study, we observed that changes in the Col I/Col III ratio and elastic fiber organization within 
vessels of bAVM may compromise the normal contraction and relaxation function of cerebral blood vessels. This loss of flexibility may contribute to the rupture of bAVM.

\section{ACKNOWLEDGMENTS}

We would like to thank Yan-Ru Guo for technical assistance.

\section{REFERENCES}

1. Arteaga-Solis E, Gayraud B, Ramirez F: Elastic and collagenous networks in vascular diseases. Cell Struct Funct 25 (2): 69-72, 2000

2. Borel JP, Bellon G: Vascular collagens. General review. Pathol Biol 33(4): 254-260, 1985

3. Choi JH, Mohr JP: Brain arteriovenous malformations in adults. Lancet Neurol 4(5): 299-308, 2005

4. da Costa L, Wallace MC, Ter Brugge KG, O'Kelly C, Willinsky RA, Tymianski M: The natural history and predictive features of hemorrhage from brain arteriovenous malformations. Stroke 40(1): 100-105, 2009

5. Holzapfel GA: Collagen in arterial walls: Biomechanical aspects. In: Fratzl P (ed), Collagen: Structure and Mechanics. New York: Springer Press, 2008: 160-172

6. Hernesniemi JA, Dashti R, Juvela S, Vaart K, Niemela M, Laakso A: Natural history of brain arteriovenous malformations: A long-term follow-up study of risk of hemorrhage in 238 patients. Neurosurgery 63(5): 823 - 831, 2008

7. Junqueira LC, Bignolas G, Brentani RR: Picrosirius staining plus polarization microscopy, a specific method for collagen detection in tissue sections. Histochem J 11(4):447 - 455, 1979

8. Junqueira LCU, Carneiro J: Basic Histology: Text \& Atlas. New York: Lange Medical Books, McGraw-Hill, Medical Pub Division, 2003

9. Kader A, Young WL, Pile-Spellman J, Mast $\mathrm{H}$, Sciacca RR, Mohr $J P$, Stein BM: The influence of hemodynamic and anatomic factors on hemorrhage from cerebral arteriovenous malformations. Neurosurgery 34 (5): 801 - 807, 1994

10. Kiernan JA: Histological and histochemical methods: Theory and practice. Bloxham: Scion, 2008

11. Lee RM: Morphology of Cerebral arteries. Pharmacol Ther 66 (1): $149-173,1995$

12. Liu Y, Zhu S, Jiao L, Wang H, Li X, Li G: Cerebral arteriovenous malformations associated with aneurysms - a report of 10 cases and literature review. J Clin Neurosci 7 (3):254-256, 2000

13. Marijianowski MM, Teeling $P$, Mann J, Becker AE: Dilated cardiomyopathy is associated with an increase in the type I/ type III collagen ratio: A quantitative assessment. J Am Coll Cardiol 25(6): 1263-1272, 1995

14. Neil-Dwyer G, Bartlett JR, Nicholls AC, Narcisi P, Pope FM: Collagen deficiency and ruptured cerebral aneurysms. A clinical and biochemical study. J Neurosurg 59(1):16-20, 1983

15. Pan L: Atlas of experimental diabetes pathology Beijing: Beijing Science Press, 2007
16. Pauschinger $M$, Knopf $D$, Petschauer $S$, Doerner A, Poller W, Schwimmbeck PL, Kühl U, Schultheiss HP: Dilated cardiomyopathy is associated with significant changes in collagen type I/III ratio. Circulation 99 (21) : 2750 - 2756, 1999

17. Pope FM, Nicholls AC, Narcisi P, Bartlett J, Neil-Dwyer G, Doshi $B$ : Some patients with cerebral aneurysms are deficient in type III collagen. Lancet 1 (8227): 973 - 975, 1981

18. Puchtler $\mathrm{H}$, Waldrop FS, Valentine LS: Polarization microscopic studies of connective tissue stained with picro-sirius red FBA. Beitr Pathol 150(2): 174 - 187, 1973

19. Redekop G, TerBrugge K, Montanera W, Willinsky R: Arterial aneurysms associated with cerebral arteriovenous malformations: Classification, incidence, and risk of hemorrhage. J Neurosurg 89 (4): 539 - 546, 1998

20. Rich L, Whittaker P: Collagen and Picrosirius red staining: A polarized light assessment of fibrillar hue and spatial distribution. Braz J Morphol Sci 22(2): 97 - 104, 2005

21. Rizzoni D, Paiardi S, Rodella L, Porteri E, De Ciuceis C, Rezzani R, Boari GE, Zani F, Miclini M, Tiberio GA, Giulini SM, Rosei $C A$, Bianchi $R$, Rosei EA: Changes in extracellular matrix in subcutaneous small resistance arteries of patients with primary aldosteronism. J Clin Endocrinol Metab 91(7): 2638 - 2642, 2006

22. Shekhonin BV, Domogatsky SP, Muzykantov VR, Idelson GL, Rukosuev VS: Distribution of type I, III, IV and V collagen in normal and atherosclerotic human arterial wall: Immunomorphological characteristics. Coll Relat Res 5(4): 355 - 368, 1985

23. Stapf C, Mohr JP, Pile-Spellman J, Sciacca RR, Hartmann A, Schumacher HC, Mast $\mathrm{H}$ : Concurrent arterial aneurysms in brain arteriovenous malformations with haemorrhagic presentation. J Neurol Neurosurg Psychiatry 73(3): 294 - 298, 2002

24. Stefani MA, Porter PJ, terBrugge KG, Montanera W, Willinsky RA, Wallace MC: Angioarchitectural factors present in brain arteriovenous malformations associated with hemorrhagic presentation. Stroke 33(4): 920 - 924, 2002

25. van den Berg JSP, Limburg M, Pals G, Arwert F, Westerveld A, Hennekam RC, Albrecht KW: Some patients with intracranial aneurysms have a reduced type III type I collagen ratio - A case-control study. Neurology 49(6): 1546 - 1551, 1997

26. von der Mark K: Localization of collagen types in tissues. Int Rev Connect Tissue Res 9:265 - 324, 1981

27. Whittaker P, Kloner RA, Boughner DR, Pickering JG: Quantitative assessment of myocardial collagen with picrosirius red staining and circularly polarized light. Basic Res Cardiol 89(5): 397-410, 1994

28. Yasargil MG: Pathological considerations. In: Yasargil MG, (ed): Microneurosurgery. Stuttgart; New York: Georg Thieme Verlag, 1987: 49-212

29. Zhang H, Sun L, Wang W, Ma X: Quantitative analysis of fibrosis formation on the microcapsule surface with the use of picro-sirius red staining, polarized light microscopy, and digital image analysis. J Biomed Mater Res A 76(1): 120 - 125, 2006 